\title{
Dielectrophoresis Effect of Dielectric Liquids with Suspended Cellulose Impurities under DC Electric Field
}

\author{
Muhamad Hafiy Syazwan Zainoddin ${ }^{1}$, Hidayat Zainuddin², Aminudin Aman \\ High Voltage Engineering Research Laboratory, Faculty of Electrical Engineering, \\ Universiti Teknikal Malaysia Melaka, Hang Tuah Jaya, 76100 Durian Tunggal, Melaka Malaysia
}

\begin{tabular}{|c|c|}
\hline Article Info & ABSTRACT \\
\hline Article history: & For decades, petroleum-based mineral oils are the insulating media \\
\hline Received Sep 2, 2016 & conventionally used in the industry, particularly for high voltage (HV) \\
\hline Revised Aug 2, 2017 & growing interest in replacing these oils with environmentally friendly \\
\hline Accepted Aug 30, 2017 & $\begin{array}{l}\text { alternatives in order to fulfill the demanding requirements of dielectric } \\
\text { liquids. One of the promising substitutes for mineral oils is ester oils. }\end{array}$ \\
\hline Keyword: & $\begin{array}{l}\text { Nevertheless, the implementation of ester oils is not widespread compared } \\
\text { with mineral oils due to the lack of understanding on the performance of }\end{array}$ \\
\hline Mineral oil & ester oils in HV applications. Hence, the objective of this study is to \\
\hline Ester oil & investigate the bridging phenomenon of two dielectric liquids with different \\
\hline Bridging & current electric field. The results show that oil viscosity plays an important \\
\hline Cellulose pressboard & role in the formation of cellulose bridge and breakdown behavior. \\
\hline Dielectrophoresis & \\
\hline
\end{tabular}

Copyright $\odot 2017$ Institute of Advanced Engineering and Science. All rights reserved.

\section{Corresponding Author:}

Muhamad Hafiy Syazwan Zainoddin,

High Voltage Engineering Research Laboratory, Faculty of Electrical Engineering,

Universiti Teknikal Malaysia Melaka,

Hang Tuah Jaya, 76100 Durian Tunggal, Melaka, Malaysia.

Email: hafiyzainoddin@gmail.com

\section{INTRODUCTION}

Power transformers are one of the crucial elements of power distribution networks. Most of the power transformers in current use are oil-immersed power transformers. Insulating liquids are used to provide insulation in these HV systems. Due to the thermo-conduction properties of insulating liquids, these liquids also serve as heat dissipation media in HV systems. Naphthenic mineral oils (which are essentially petroleum-derived oils) are widely used as transformer insulating liquids. Nonetheless, due to the depletion of fossil fuels, flammability, and negative environmental impact of mineral insulating oils, there is growing interest in the scientific community to replace these oils with ester oils in power transformers [1]-[3]. In addition, the enforcement of stringent environmental protection regulations encourage $\mathrm{HV}$ equipment manufacturers and operators to use biodegradable liquids with low toxicity as insulating liquids [1],[3]-[6].

Despite the potential of ester oils as insulating liquids, there is a lack of understanding on the dielectric properties of these oils, especially in direct current energization. In recent years, advances in high voltage direct current (HVDC) equipment have made it necessary to gain in-depth understanding on the dielectric behavior of insulating liquids under alternating current (AC) and direct current (DC) electric stresses [7]. These HVDC systems are suitable for long-distance electrical power transmission. Moreover, with the introduction of renewable sources, this approach has attracted the attention of the power industry for transmission of electrical power generated by offshore wind farms. In addition, some components of HVDC systems are subjected to AC and DC voltages such as HVDC converter transformers. Thus, it is important to investigate and understand the properties of dielectric liquids under both $\mathrm{AC}$ and DC electric fields. 
Moreover, it has been reported that the rate of failure of HVDC transformers is 5-10 times higher than that of conventional transmission transformers [7].

When the transformer is in operation, the dielectric liquid is in contact with other internal components such as insulation paper, iron cores, and metals [8]. This may lead to the presence of impurities such as cellulose pressboard particles in the dielectric liquid due to the thermal and electrical stresses. This in turn, results in bridging during the operating period since the high voltage generates a strong electric field in the transformer. Initially, the particles tend to move toward the high field region due to the dielectrophoresis (DEP) effect during the transformer operation. Then, forces as a result of DEP will promote the formation of cellulose bridge between two different potentials after a certain period [9]. DEP is defined as the interaction between the dipole of the particles and spatial gradients in the non-uniform electric field, which results in motion of the impurity particles. This DEP force does not require a change in the particles, and only occurs when polarized particles are suspended in a non-uniform electric field [10]. The magnitude of the induced dipole depends on the polarizability of the particles with respect to the medium [9]. The DEP effect is widely used in biochemistry to separate proteins from nucleic acids in foods [11]. This study is focused on the DEP effect in two types of dielectric liquids with different viscosities: (1) palm fatty acid ester (PFAE) oil, and (2) Gemini X mineral oil. These insulating oils are compared to determine how the DEP effect influences the formation of a complete cellulose bridge as well as DC breakdown voltage.

\section{EXPERIMENTAL SETUP}

A 1.5-liter rectangular glass test cell was used in the experiments. Two sphere electrodes (each with a diameter of $13 \mathrm{~mm}$ ) were placed in the middle of the test cell. The gap between the electrodes was kept fixed at $10 \mathrm{~mm}$, as shown in Figure 1. One of the spherical electrodes was attached to the HVDC supply whereas the other was connected to the ground. Haefely High Voltage Training Modular was used to supply the HVDC to the system and have a capability up to $100 \mathrm{kV}$. A Nikon D5300 hybrid digital lens reflex camera was mounted on top of the test cell to capture optical images of the cellulose bridging phenomenon.

\subsection{Preparation of Oil Samples}

Two types of dielectric liquids were used in the experiments: (1) PFAE oil and (2) Nytro Gemini X mineral oil. Karl Fischer titration method was used to monitor the moisture content of the oil samples. This method is one of analytical techniques that most frequently used in laboratories around the world to measure water (moisture) content [6]. Furthermore, this step is crucial because the dielectric constants and conductivities of the oil and pressboard particles will be affected by the presence of moisture in the oil. The moisture content of the oil samples was found to be within $150 \pm 10 \mathrm{ppm}$ and $50 \pm 10 \mathrm{ppm}$ for the PFAE and Gemini X insulating oils, respectively. The properties of the PFAE and Gemini X insulating oils are presented in Table 1.

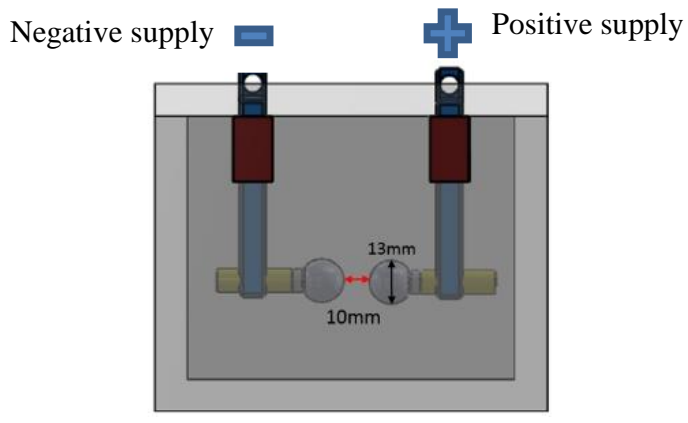

Table 1. Properties of the PFAE and Gemini X insulating oils

\begin{tabular}{lcc}
\hline \multicolumn{1}{c}{ Property } & PFAE oil & $\begin{array}{c}\text { Gemini X } \\
\text { mineral oil }\end{array}$ \\
\hline Density $\left(\mathrm{g} / \mathrm{dm}^{3}\right)$ & 0.86 & 0.87 \\
Viscosity $\left(\mathrm{mm}^{2} / \mathrm{s}\right)$ & 5.06 & 0.09 \\
Pour point $\left({ }^{\circ} \mathrm{C}\right)$ & -32.5 & -51 \\
Fully biodegradable & Yes & No \\
\hline
\end{tabular}

Figure 1. Test cell configuration

\subsection{Preparation of the Pressboard Dust}

A piece of new cellulose pressboard was scraped to simulate the presence of contaminants in the dielectric liquids. In this study, only $500 \mu \mathrm{m}$ of particles with a concentration of $0.001 \mathrm{~g}$ with respect to the oil mass were used in the experiments. The size of the particles was measured based on the fiber width rather than the length throughout the experiments. 


\section{EXPERIMENTAL PROCEDURE}

Firstly, $1 \mathrm{~L}$ of insulating oil was added into the test cell such that the electrodes were submerged in the oil. Next, the cellulose particles were added into the oil and the contaminated oil was stirred for 2-3 min to distribute the particles evenly. The contaminated oil was tested under the influence of a DC electric field. The tested oil was replaced with new oil after each bridging experiment. It shall be noted that prior to the oil change, the test cell was cleaned using $n$-hexane solution in order to remove pressboard residues from the walls of the test cell.

The bridging experiment was conducted by applying HVDC to one of the electrodes whereas the other electrode was earthed. The voltage was applied in steps of $5 \mathrm{kV}$ with a 1-min interval for each step until breakdown occurs. However, for the first three steps, the voltage was increased to 2,7 , and $10 \mathrm{kV}$. This was done to observe the DEP phenomenon (particle motion) from static condition until the formation of a complete bridge between the electrodes. The delay between the voltages was 3-5 s. Each experiment was repeated five times to observe the repeatability and reproducibility of the results.

\section{RESULTS AND DISCUSSION}

In general, the bridging process can be divided into five distinct stages, as described below.

\section{Stage One}

Once HVDC is applied to the system, the cellulose particles begin to polarize under the influence of the DC electric field and the particles move between the electrodes, as shown in Figure 2. Polarization occurs when external materials are present in the electric field. This may lead to DEP due to the influence of a nonuniform DC electric field. Polarization occurs within a voltage range of $0-2 \mathrm{kV}$.

\section{Stage Two}

In this stage, some of the cellulose particles move toward the electrode surface. The particles begin to acquire and produce charges upon contact with the electrode surface, as shown in Figure 3. After the particles are charged several times, the particles tend to pull themselves from the electrode surface and move toward the other electrode due to the DEP force, Coulomb force, and drag force from the viscous oil. The movement of the particles in this stage is rather slow. The particles begin to attach themselves onto the electrode surface due to the repelling Coulomb and attracting charges. This stage occurs when the HVDC supply is within a range of $2-7 \mathrm{kV}$.

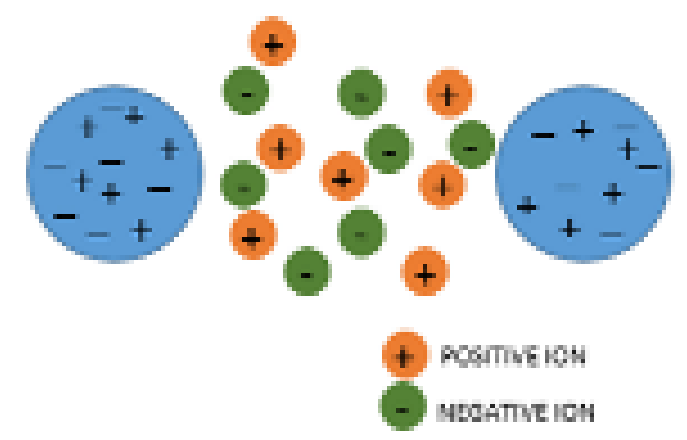

Figure 2. Movement of cellulose particles once HVDC is applied to the system

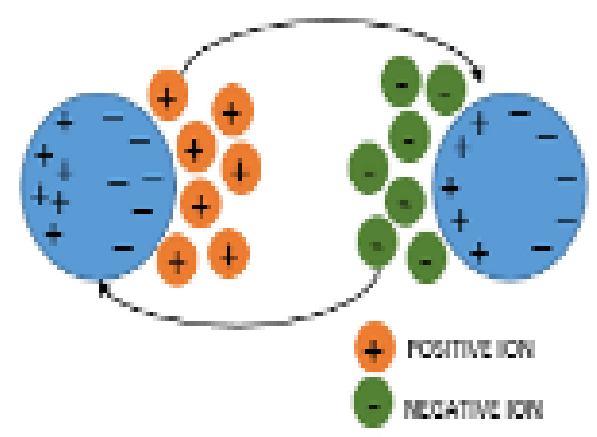

Figure 3. Cellulose particles after the polarization process

\section{Stage Three}

In this stage, more cellulose particles are attracted toward the electrodes. The particles begin to align themselves in parallel with the electric field generated between the two electrodes due to DEP force, as shown in Figure 4. The particles begin to travel back and forth between the electrodes and attach themselves on the electrode surface. The chain of cellulose particles can be typically observed in this stage. This chain increases towards the mid-point between the electrodes, which causes the maximum electric field to be distributed further away from the electrode surface (i.e., at the tip of the cellulose particles). It is believed that this phenomenon occurs due to the distribution of the electric field generated between the electrodes and cellulose particles attached on the electrode surface. In addition, it has been reported that the cellulose bridge 
connecting the two electrodes enables a very small conduction current (in the order of $10^{-9}$ ) to flow between the electrodes [12].

In addition, some of the cellulose particles remain attached to the electrode surface. This behavior is due to the DEP effect which prevents the particles from acquiring sufficient charge. Due to the distribution of electric field between the electrodes, these particles attract other free cellulose particles in the insulating oil with opposite charges. Multiple thin bridges become apparent with time along with a voltage increase, and the cellulose particles continue to accumulate until these bridges become interconnected to form a dense, wide, and thick bridge. This stage takes place when the HVDC supply is within a range of $7-40 \mathrm{kV}$.

\section{Stage Four}

In this stage, the cellulose particles travel at higher velocities as the HVDC approaches the DC breakdown voltage, as shown in Figure 5. This is due to the faster charging-discharging rate as well as repelling-attracting force (Coulomb force effect) between the cellulose particles and electrodes as a result of the higher DC electric field within the system. When the HVDC is increased further, the cellulose particles travel back and forth again (but at higher velocities). This includes the cellulose particles within the bridge until breakdown occurs. The bridge narrows in the middle and becomes broader at the end of the bridge (electrode surface). When the HVDC exceeds the breakdown voltage, insulation breakdown finally occurs and the insulating oil becomes corrugated. This stage occurs when the HVDC supply is increased from $40 \mathrm{kV}$ until breakdown. When breakdown occurs, explosion is observed between the electrodes, followed by the generation of bubbles in the oil. Previous studies have shown that these bubbles are produced through the conduction currents between the electrodes [13].

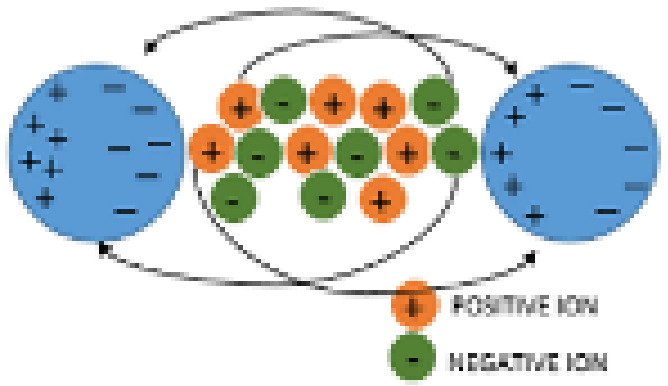

Figure 4. Alignment of the cellulose particles during the bridging process

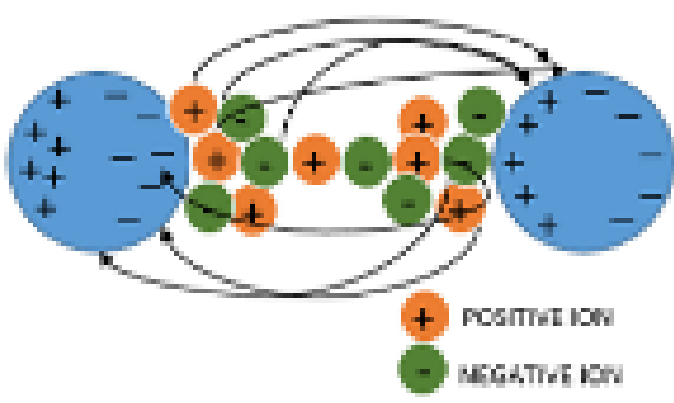

Figure 5. Cellulose particles travelling back and forth between the electrodes at higher velocities until breakdown occurs

\section{Stage Five}

In this stage, the cellulose particles burst and scatter toward the bottom of the test cell after breakdown occurs because the gravity effect is greater compared with the DEP effect.

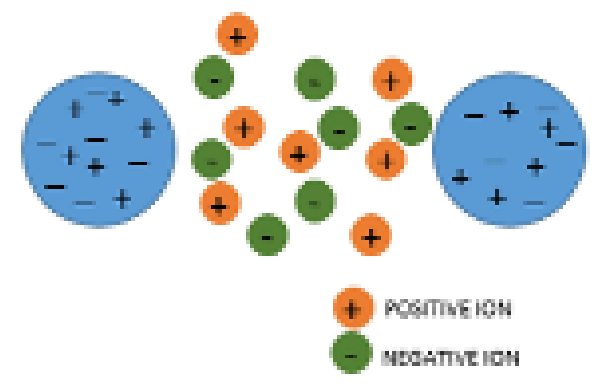

Figure 6. Bursting of cellulose particles in the bridge after breakdown occurs 


\subsection{Palm fatty acid ester oil Stage One}

After applying $2 \mathrm{kV}$ of HVDC, the particles begin to move toward the electrode surface due to the distribution of the electric field. It takes about $50 \mathrm{~s}$ to start the polarization process and thereafter, the cellulose particles begin to move toward the electrode surface.

\section{Stage Two}

Next, the HVDC is increased to $7 \mathrm{kV}$ and it is apparent that the cellulose particles begin to move rapidly compared with that when the HDVC is $2 \mathrm{kV}$. A thin bridge forms between the electrodes as a result of the continuous elongation of the cellulose branches from both electrodes after $10 \mathrm{~s}$ of increasing the HVDC supply. This stage is shown in Figure 7 (STAGE 2). It can be seen that more cellulose particles seem to be attracted toward the electrode surface.

\section{Stage Three}

The cellulose bridge becomes denser and thicker as a result of the accumulation and multiplication of cellulose branches when the HDVC is increased, as shown in Figure 7 (STAGE 3, Image IV). This behavior is caused by the maximum electric field at the tips of the cellulose particles within the boundaries of the cellulose bridge, which represents the DEP force. It can be observed from Figure 7 that more particles are attached onto the electrode that is connected to the HVDC supply compared with the grounded electrode (STAGE 3, Image IV). This phenomenon occurs as soon as the particles begin to attach themselves onto the electrode surface due to the electric field generated between the electrodes.

\section{Stage Four}

In this stage, the cellulose particles seem to travel at higher velocities. The bridge becomes denser as the HVDC approaches the DC breakdown voltage. Consequently, the oil becomes corrugated (STAGE 4, Image IV). However, there is no luminous flashover or formation of bubbles when breakdown occurs.

\section{Stage Five}

After breakdown occurs, the cellulose particles burst and scatter toward the bottom of the test cell due to the gravity effect (STAGE 5, Image III). This situation is different from that when the supply voltage is switched off before breakdown occurs [14].

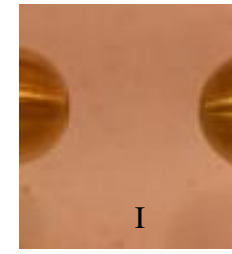

STAGE 1
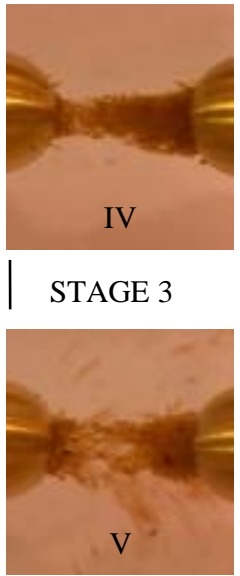

STAGE 4

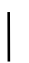

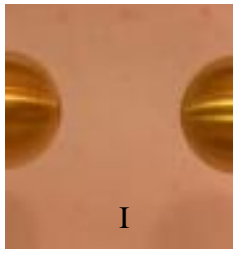

STAGE 2
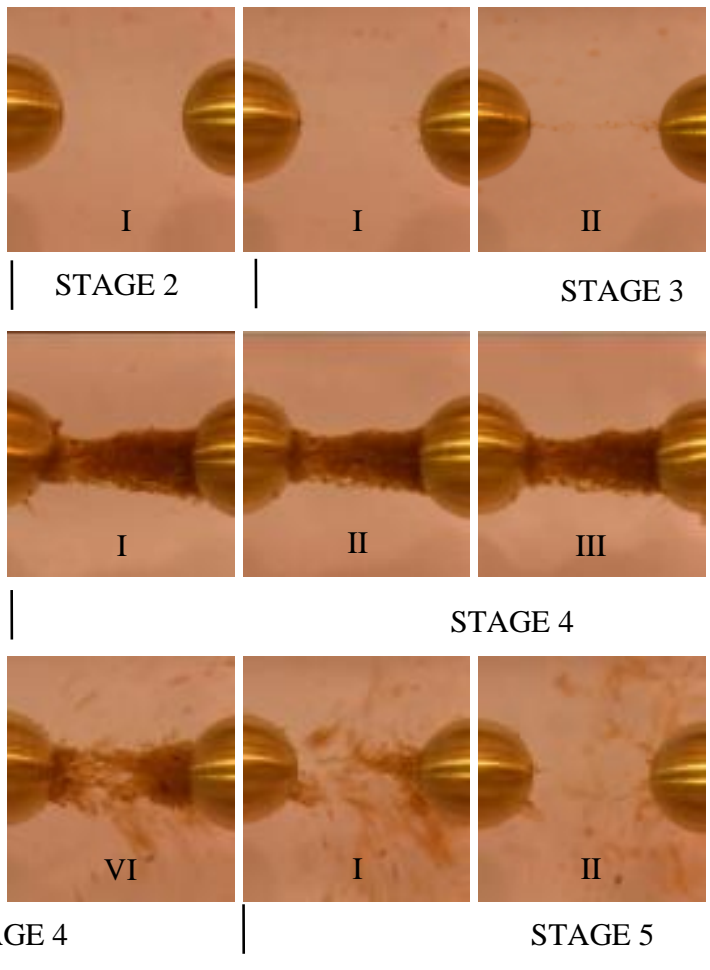

STAGE 3
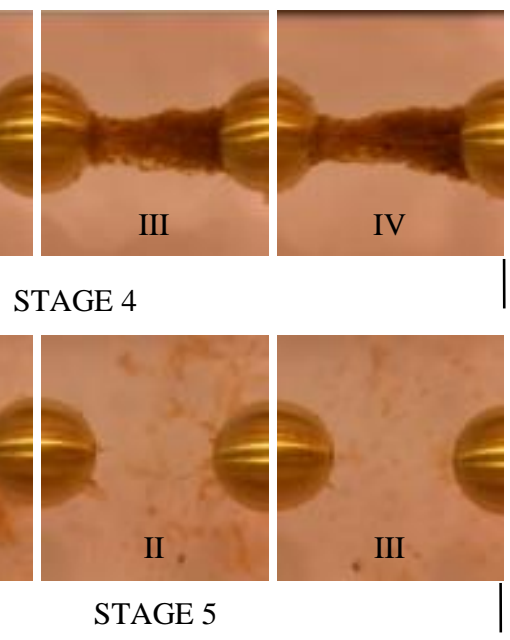

Figure 7. Cellulose bridging process in the PFAE oil 


\subsection{Gemini $X$ mineral oil Stage One}

The cellulose particles appear to experience DEP after $37 \mathrm{~s}$ of applying $2 \mathrm{kV}$ of HVDC to the system. It is observed that the cellulose particles move at higher velocities compared with those observed for the PFAE oil. This is indeed expected since the viscosity of the Gemini X mineral oil is lower than that for the PFAE oil. This leads to faster motion of the cellulose particles since there is less friction between the particles and viscous oil.

\section{Stage Two}

In this stage, the cellulose particles begin to navigate toward the electrode surface and consequently, the chain of cellulose particles increases toward the mid-point between the electrodes. When the HVDC supply is increased to $7 \mathrm{kV}$, a thin bridge forms after $6 \mathrm{~s}$, as a result of continuous elongation of the cellulose branches from both electrodes.

\section{Stage Three}

In this stage, it is apparent that more cellulose particles are attracted to the electrode surface. However, the thickness of the cellulose bridge remains the same even when the HVDC supply is increased, unlike the thickness of the cellulose bridge observed for the PFAE oil. In addition, some of the cellulose particles adhere to the bottom of the test cell, which reduces the thickness and density of the cellulose bridge. When the HVDC supply is increased further to $25 \mathrm{kV}$, it is observed that there is luminous flashover between the electrodes that does not lead to a complete breakdown. This is similar to the non-breakdown breakdown event when a positive streamer bridges an open oil gap as reported in [15]-[18] and full discharge event during surface discharge at the oil pressboard interface in [19]-[21]. This phenomenon recurs when the HVDC supply is increased further, as shown in Figure 8 (STAGE 3, Images II and III).

\section{Stage Four}

When the HVDC approaches the DC breakdown voltage, the particles travel at a higher velocity and the oil appears corrugated due to the higher electric field. The thickness of the cellulose bridge remains the same as that in the previous stage. When breakdown occurs, there is explosion with bright flashover as well as the presence of bubbles (STAGE 4, Image VI).

\section{Stage Five}

Similar conditions are observed in this stage as those in the previous stage. Immediately after breakdown, the cellulose particles burst and scatter toward the bottom of the test cell due to the gravity effect (STAGE 5, Image III).
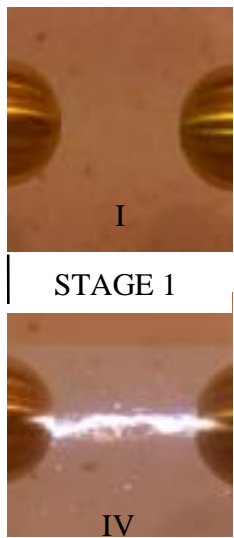

STAGE 3

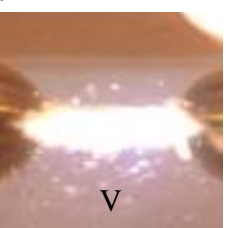

STAGE 4

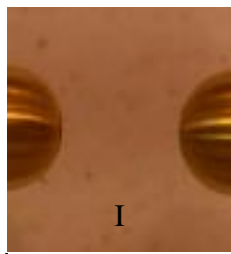

STAGE 2
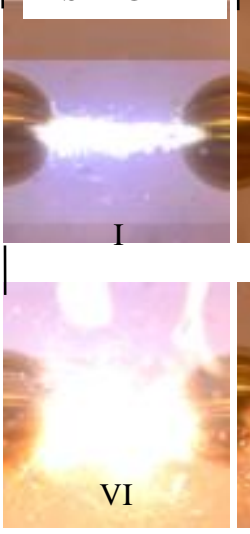

VI

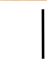

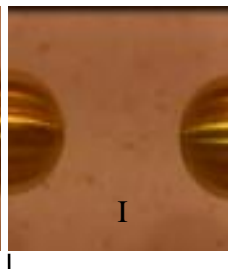
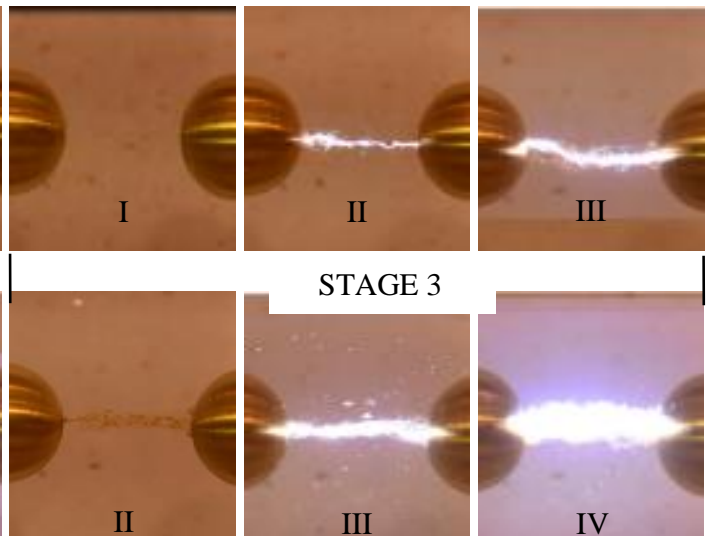

STAGE 3

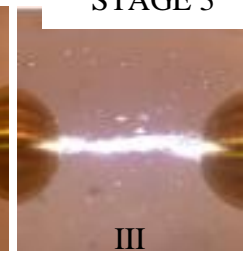

STAGE 4

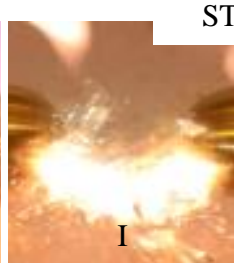

I

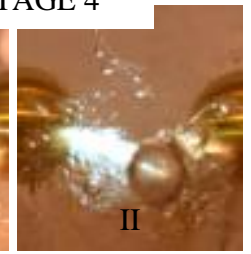

STAGE 5

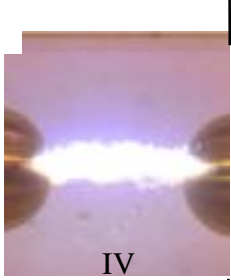

Figure 8. Cellulose bridging process in the GEMINI X mineral oil 
It is evident from Figures 7 and 8 (STAGE 4, Image II) that the thickness and density of the cellulose bridge are different for the PFAE and Gemini X insulating oils. The thickness of the cellulose bridge in the PFAE oil increases with an increase in the HVDC supply. In contrast, the thickness of the cellulose bridge remains the same for the Gemini X mineral oil even when the HVDC supply is increased. It is believed that this is due to less friction between the cellulose particles and insulating oil as well as faster charging-discharging rate, which cause the particles to move from one electrode to another. Since the PFAE oil has higher viscosity, there is more friction between the cellulose particles and oil while chargingdischarging rate is slower. Consequently, the charged particles are more attracted to the nearest charged particles, which are at the mid-point between the two electrodes.

Figures 7 and 8 shows that the cellulose bridge bursts when breakdown occurs (STAGE 4, Image VI). It can be observed that there is high intensity of luminous flashover between the electrodes for the Gemini X mineral oil. However, a different case is observed for the PFAE oil, where the cellulose particles burst without any luminous flashover during breakdown. The former case suggests that there are currents traveling in the bulk oil, which lead to luminous breakdown. In the latter case, it appears that the breakdown currents travel through the cellulose particles. The HVDC is small in the initial stage of the experiment; however, the cellulose particles become charged when the HVDC is increased further. Thus, when the HVDC reaches its saturated level, the current will flow through the cellulose particles between the electrodes, leading to breakdown. Several researchers have also observed this phenomenon [12],[22],[23].

The characteristics of the cellulose bridge phenomenon for the PFAE and Gemini X insulating oils with and without cellulose pressboard dust (contaminant) are summarized in Table 2. It can be seen that the PFAE oil has better performance compared to the Gemini X oil, which is evidenced from the higher value for each characteristic. It can be observed from both oils that the cellulose particles begin to move toward the electrode surface after applying $2 \mathrm{kV}$ of HVDC supply. A complete bridge is observed after the HVDC supply is increased to $7 \mathrm{kV}$. The oil becomes corrugated as the HVDC is increased further until breakdown occurs. This is due to the conduction currents which contribute to disturbance in the oils [24].

Table 2. Comparison of the characteristics of the cellulose bridge phenomenon for the PFAE and Gemini X insulating oils

\begin{tabular}{|c|c|c|c|c|}
\hline \multirow{2}{*}{ Characteristic } & \multicolumn{2}{|c|}{ PFAE oil } & \multicolumn{2}{|c|}{ Gemini X mineral oil } \\
\hline & With contaminant & Without contaminant & With contaminant & Without contaminant \\
\hline $\begin{array}{l}\text { Time taken for the } \\
\text { particles to attach } \\
\text { themselves onto the } \\
\text { electrode surface }\end{array}$ & $50 \mathrm{~s}$ at $2 \mathrm{kV}$ & - & $37 \mathrm{~s}$ at $2 \mathrm{kV}$ & - \\
\hline $\begin{array}{c}\text { Time taken to form a } \\
\text { complete cellulose } \\
\text { bridge }\end{array}$ & $76 \mathrm{~s}$ at $7 \mathrm{kV}$ & - & $66 \mathrm{~s}$ at $7 \mathrm{kV}$ & - \\
\hline $\begin{array}{l}\text { DC breakdown } \\
\text { voltage }\end{array}$ & $61.62 \mathrm{kV}$ & $57.85 \mathrm{kV}$ & $55.34 \mathrm{kV}$ & $50.40 \mathrm{kV}$ \\
\hline Thickness level & High & - & Lower & - \\
\hline $\begin{array}{l}\text { Luminous flashover } \\
\text { during breakdown }\end{array}$ & No & No & High Intensity & Low Intensity \\
\hline
\end{tabular}

In addition, the oil viscosity plays a significant role in the time taken for the cellulose particles to attach themselves onto the electrode surface and the time taken to complete the formation of the cellulose bridge. It can be clearly seen from Table 2 that both of the aforementioned parameters are always shorter for the Gemini X mineral oil due to its lower viscosity compared with the PFAE oil. This reduces friction when the cellulose particles are in motion.

\section{CONCLUSION}

The effects of cellulose pressboard contaminant on the dielectric performance of two types of insulating oils (PFAE oil and Gemini X mineral oil) were investigated in this study. Based on the experimental results, it can be concluded that the oil viscosity plays an important role in the formation of cellulose bridge and breakdown behavior. The friction mechanism during the particle motions due to DEP affects the breakdown behavior. In general, the DC breakdown voltage varies depending on the type of insulation oil, where the value is higher for the PFAE oil because of its higher viscosity. In addition, the time taken to form a complete cellulose bridge and the DC breakdown voltage are useful indicators which will enable operators to assess the performance of PFAE oil in HV systems. 


\section{ACKNOWLEDGMENTS}

The authors wish to extend their utmost appreciation to the Universiti Teknikal Malaysia Melaka and Ministry of Higher Education, Malaysia for the encouragement and financial support. This work is under Fundamental Research Grant Scheme (FRGS/1/2014/TK0/FKE/02/F00216). A big appreciation also to the Malaysia Transformer Manufacturing Sdn. Bhd. (MTM) for their courtesy in supplying pressboard.

\section{REFERENCES}

[1] T. V. Oommen, et al., "Biodegradable electrical insulation fluids," Proc. Electr. Insul. Conf. Electr. Manuf. Coil Wind. Conf., pp. 465-468, 1997.

[2] S. S. Kumar, "Analysis of Vegetable Liquid Insulating Medium for Applications in High Voltage Transformers," Int. Conf. on Science, Engineering and Management Research., 2014.

[3] M. Svoboda and P. Trnka, "Alternative electrical insulating fluids in power transformers," Electric Power Engineering (EPE), pp. 3-6, 2014.

[4] B. Dolata, et al., "New synthetic ester fluid for the insulation of liquid immersed transformers," Conf. Rec. 2006 IEEE Int. Symp. Electr. Insul., pp. 534-537, 2006.

[5] H. B. H. Sitorus and R. Setiabudy, "Physicochemical and Electrical Properties of Jatropha Curcas Methyl Ester Oil as a Substitute for Mineral Oil," IEEE Conf. on Liquid, Dielectrics., pp. 1-4, 2014.

[6] T. V. Oommen, "Vegetable oils for liquid-filled transformers," IEEE Electr. Insul. Mag., vol. 18, pp. 6-11, 2002.

[7] "Innovation Funding Incentive. Electricity transmission R\&D Program detailed report," Annual Reports, National Grid Plc, London, UK, 2011/2012.

[8] M. G. Danikas, "Breakdown of transformer oil," IEEE Electr. Insul. Mag., vol/issue: 6(5), pp. 27-34, 1990.

[9] N. G. Green, "Dielectrophoresis and AC electrokinetics," in Electrokinetics and Electrohydrodynamics in Microsystems, A. Ramos, Ed. SpringerWienNewYork, pp. 61-84, 2011.

[10] H. A. Pohl, "The motion and precipitation of suspensoids in divergent electric fields," J. Appl. Phys., vol/issue: 22(7), pp. 869-871,1951

[11] D. Sheehan, "Physical biochemistry: principles and applications," John Wiley \& Sons, 2009.

[12] S. Mahmud, et al., "Experimental Studies of influence of DC and AC Electric Fields on Bridging in Contaminated Transformer Oil," Dielectr. Electr. Insul. IEEE Trans., vol/issue: 22(1), pp. 152-160, 2015.

[13] A. Beroual, et al., "Pre-breakdown Phenomena in Synthetic Ester and Silicone Oils for Power Transformers," IEEE Conf. of Dielectric Liquids, pp. 1-4, 2008.

[14] S. Mahmud, et al., "Bridging in contaminated transformer oil under DC and AC electric field," J. Phys. Conf. Ser., vol. 472, pp. 12007, 2013.

[15] P. Rain and O. Lesaint, "Prebreakdown phenomena in mineral oil under step and ac voltage in large-gap divergent fields," IEEE Transaction on Dielectrics and Electrical Insulation, vol. 1, pp. 697-701, 1994.

[16] O. Lesaint, et al., "Streamer propogation and breakdown under ac voltage in very large oil gaps," IEEE Transaction on Dielectrics and Electrical Insulation, vol. 5, pp. 351-359, 1998.

[17] O. Lesaint and G. Massala, "Positive streamer propagation in large oil gaps: Experimental characterization of propagation modes," IEEE Transaction on Dielectrics and Electrical Insulation, vol. 5, pp. 360-370, 1998.

[18] L. Lundgaard, et al., "Propagation of positive and negative streamers in oil with and without pressboard interface," IEEE Transaction on Dielectrics and Electrical Insulation, vol. 5, pp. 388-395, 1998.

[19] H. Zainuddin, et al., "Characteristics of leakage current during surface disharge at the oil-pressboard interface," 2012 Annual Report Conference on Electrical Insulation and Dielectric Phenomena (CEIDP), Montreal, Canada, pp. 483-486, 2012.

[20] N. A. Othman, et al., "Investigation on the degradation behavior of creepage discharge on pressboard immersed in palm fatty acid ester (PFAE) oil," Jurnal Teknologi, vol/issue: 10(3), pp. 31-36, 2016.

[21] N. A. Othman, et al., "The correlation between surface tracking and partial discharge characteristics on pressboard surface immersed in MIDEL eN," International Journal of Electrical and Computer Engineering (IJECE), vol/issue: 7(2), pp. 631-640, 2017.

[22] G. Chen and M. H. Zuber, "Pre-breakdown characteristics of contaminated power transformer oil," Annu. Rep. Conf. Electr. Insul. Dielectr. Phenomena, CEIDP, pp. 659-662, 2007.

[23] S. Mahmud, et al., "Bridging phenomenon in contaminated transformer oil," Proc. 2012 IEEE Int. Conf. Cond. Monit. Diagnosis, September, pp. 180-183, 2012

[24] A. Beroual and S. Bouazabia, "Mechanisms involed in the generation of gaseous bubbles in liquid dielectrics under DC voltage.," Arch. Electr. Eng.,vol. 48, pp. 295-303, 1999. 